\title{
Journey of the Human Papillomavirus (HPV) in a Developing Country over 5 Years (2010 - 2015)
}

\author{
M Danial ${ }^{1,2 *}$, S Sivasangari ${ }^{1,2}$, AL Arulappen ${ }^{3}$, LM Ong $^{1}$
}

\begin{abstract}
Human papillomavirus (HPV) is a prevalent sexually transmitted infection with serious medical, sexual, and relationship consequences. HPV vaccine protection is available globally but unfortunately vaccine uptake is inconsistent everywhere. From this study, it was observed that the awareness of cervical cancer, HPV virus and HPV vaccination in Malaysia is high, at $83.1 \%, 73.9 \%$ and $73.3 \%$ of respondents, respectively. However, a considerably low percentage had undergone HPV vaccination $(8.6 \%)$ compared to those who had experienced a Pap smear (32.9\%). Awareness between cervical cancer and HPV virus and vaccination was low. Health care providers and the governing bodies have to play a vital role in disseminating holistic information on the vaccine and the importance of getting vaccinated to the public more vigorously in Malaysia.
\end{abstract}

Keywords: Human papillomavirus (HPV) - HPV vaccination - HPV virus - cervical cancer - pap smear

Asian Pac J Cancer Prev, 17 (3), 1363-1368

\section{Introduction}

Global statistics on the incidence of cervical cancer indicates 527,624 new cervical cancer cases are diagnosed annually in the world. It also reported that cervical cancer is the 4th type of cancer that is detected on females and is the 2nd most common type of cancer which affects 15 to 44 years old females in the world (Bruni et al., 2014). The National Cancer Registry of Cancer Incidence in Malaysia reports that cervical cancer is the second most common cancer in women which compromises $12.9 \%$ of total female cancers (Lim and Halimah, 2003). Women are prone to this infection twice than men in all regions of the world including USA and the prevalence of Human Papillomavirus (HPV) is much higher in women than men (Faridi et al., 2011).

In addition, on average there are about 2000-3000 cases of admission early and many of which presents late stage of cancer (Ministry of Health, 1999). Thus the statistics proves the dire need to address prevalence of the cervical cancer. Cervical cancers are caused by the oncogenic human papillomavirus infection (Schiffman et al., 2007). There are several oncogenic HPV identified such as HPV-31, -51, -52, -56, -58 and -667 of which HPV-16 and HPV-18 combined contributes to about $70 \%$ of cervical cancer incidence (Cheah, 1994; Chye et al., 2005; Faridi et al., 2011). HPV16 which ultimately leads to cervical cancer stays and incubates in the body for a prolonged period of time before the onset of malignant cervical cancer (Gloria et al., 2004) which justifies the early vaccination for young females.
In many countries HPV vaccines have been made as a consented requirement for girls aged between 9 to 13 years, in addition to late vaccination at the age of 26 (PATH, 2011). The Ministry of Health Malaysia has taken significant steps in addressing this health threat by introducing the Pap smear screening program in 1969(Ministry of Health, 2004). Subsequently in year 2006, the Malaysian government provided the regulatory approval of the vaccine (Wong, 2008) and in year 2010 national HPV immunization was implemented for girls aged 13 years. The HPV-16/18 AS04-adjuvanted cervical cancer vaccine (Cervarix ${ }^{\circledR}$, GlaxoSmithKline, Rixensart, Belgium) has been licensed in more than 120 countries worldwide which includes Europe, US, India, Japan, Korea and Malaysia, and also received WHO prequalification to combat cervical cancer in developing nations (PharmaNews). In Malaysia, the AS04-adjuvanted cervical cancer vaccine was launched in 2008 (Faridi et al., 2011).

Act of prevention against cervical cancer can be divided into two major types which compromise vaccination and Pap smear. The secondary type of prevention is by the identification of precancerous lesions by cytology based Papanicolaou (Pap) smear screening (Wong, 2010). Both vaccination and Pap smear may work hand in hand in cervical cancer prevention.

Previous study on the knowledge and attitudes about HPV virus, HPV vaccine and Pap smear were conducted in year 2010 by two separate studies, one at the rural area of Perak and Pahang and the other at a selected hospital in Selangor. Both studies concluded that the participants 
M Danial et al

possess low level of knowledge on HPV and HPV vaccine and recommended education of population and limitations to being vaccinated should be addressed urgently (AlDubai et al., 2010; Wong, 2010). Therefore, in this research it is hoped that knowledge on the HPV in the areas of cervical cancer, HPV infection and HPV vaccination have increased after the 5 years of its implementation.

\section{Materials and Methods}

\section{Participants}

A cross sectional face to face study conducted from August 2014 until August 2015 among voluntary participation of 337 women at the Penang General Hospital, Malaysia. Women aged 18 and above who were able to communicate in either Bahasa Malaysia or English were included in this study. Written informed consent was obtained and brief respondent explanatory note was read out to the participants before they answered the questionnaire. The study was carried out after obtaining the approval from the Malaysia Research Ethics Committee (MREC) (Approval number: NMRR14-1496-22936(IIR)).

\section{Validity and Reliability}

The questionnaire was adopted from previous study in Malaysia (Al-Dubai et al., 2010). The Cronbach alpha of different sections of the questionnaire was between 0.681 to 0.954 , indicating good reliability (Al-Dubai et al., 2010). For the current study, the questionnaire was pilot-tested on 20 voluntary participants to test the appropriateness of the questions and their comprehension. This pilot study revealed that the questions seemed to be readily understood by those participated in the pilot.

\section{Statistical methods}

The data were entered and analyzed using the Statistical Package for Social Sciences (SPSS) base version 21.0. The study included descriptive and bivariate analysis.

\section{Results}

Table 1 illustrates the demographic characteristics of the respondents. Respondents aged between 18-30 years accounted about $43.9 \%$ of the total participant. Majority of the respondents are Malay (54.3\%), Muslim (56.1\%), married $(63.5 \%)$, employed $(81.6 \%)$, having non tertiary education level $(61.8 \%)$ the belonging to the groups with either 1-3 children or 4 or more children (each 20.8\%) and residing in the urban locality $(60.5 \%)$.

\section{Awareness on cervical cancer, HPV virus and HPV vaccination}

Awareness on cervical cancer, HPV virus and HPV vaccine of the respondents were accessed by simply questioning them if they had heard of the three. Awareness on cervical cancer are significantly associated with marital status $(\mathrm{p}=0.007)$ and level of education level $(\mathrm{p}=0.035)$. Another factor that almost significant is the number of children ( $\mathrm{p}=0.057)$. Married respondents have the highest level of awareness $(84.1 \%)$ with the adjusted odd ratio
(OR) of 30.60 and high level confidence interval (CI) which skew to the right of compared single and divorced. There was also significant difference between group with tertiary and non-tertiary education. Strong cervical cancer awareness was associated with group with tertiary level of education. Other demographic factors like age group, ethnicity, locality and employment status were not significant $(\mathrm{p}<0.05)$ factors that are associated with the awareness on cervical cancer. In terms of awareness on HPV virus, demographic factors like age group and locality are significantly associated with the awareness on HPV virus. There are significant difference between the age groups with the respondents aged 41 and above have very little awareness on the virus with the $95 \% \mathrm{CI}$ value of less than one (0.04-0.61). The same scenario was observed in the semi urban locality, with the awareness level of less than one based on $95 \%$ CI (0.10-0.64). Other demographic factors like ethnicity, marital status, number of children, employment status and education level were not significant $(\mathrm{p}<0.05)$ factors that are associated with

Table 1. Demographic Characteristics of the Respondents $(\mathbf{n}=337)$

\begin{tabular}{|c|c|c|}
\hline Characteristics & Number (n) & Percentage $(\%)$ \\
\hline \multicolumn{3}{|l|}{ Age group (years) } \\
\hline $18-30$ & 148 & 43.9 \\
\hline $31-40$ & 118 & 35.0 \\
\hline$\geq 41$ & 71 & 21.1 \\
\hline \multicolumn{3}{|l|}{ Ethnicity } \\
\hline Malay & 183 & 54.3 \\
\hline Indian & 72 & 21.4 \\
\hline Chinese & 66 & 19.6 \\
\hline Others & 16 & 4.7 \\
\hline \multicolumn{3}{|l|}{ Religion } \\
\hline Muslim & 189 & 56.1 \\
\hline Buddhist & 51 & 18.4 \\
\hline Hindu & 62 & 15.1 \\
\hline Others & 35 & 10.4 \\
\hline \multicolumn{3}{|l|}{ Marital Status } \\
\hline Single & 116 & 34.4 \\
\hline Married & 214 & 63.5 \\
\hline Divorced & 7 & 2.1 \\
\hline \multicolumn{3}{|l|}{ Employment status } \\
\hline $\begin{array}{l}\text { Employed (full time, part } \\
\text { time and self employed) }\end{array}$ & 275 & 81.6 \\
\hline $\begin{array}{l}\text { Unemployed (Studying, } \\
\text { Not working and Retired) }\end{array}$ & 62 & 18.4 \\
\hline \multicolumn{3}{|l|}{ Education } \\
\hline Non Tertiary level & 208 & 61.8 \\
\hline Tertiary level & 129 & 38.3 \\
\hline \multicolumn{3}{|l|}{ Number of children } \\
\hline No children & 47 & 13.9 \\
\hline 1-3 children & 70 & 20.8 \\
\hline$\geq 4$ children & 70 & 20.8 \\
\hline \multicolumn{3}{|l|}{ Locality } \\
\hline Urban & 204 & 60.5 \\
\hline Semi-Urban & 64 & 19.0 \\
\hline Rural & 69 & 20.5 \\
\hline
\end{tabular}




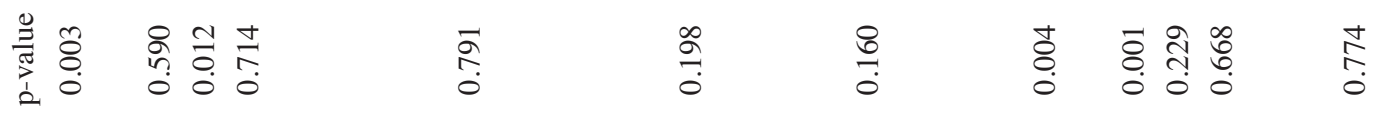

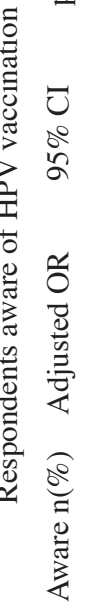

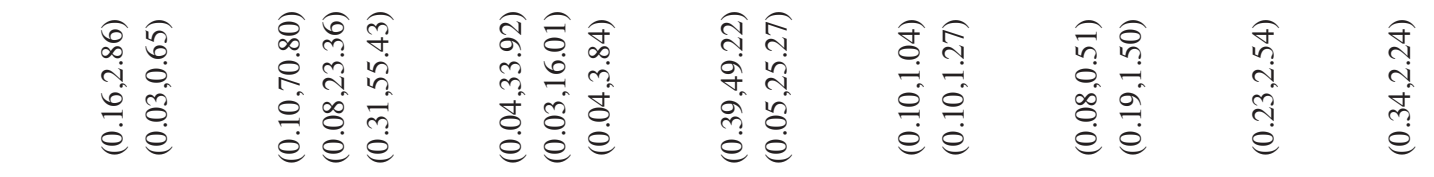

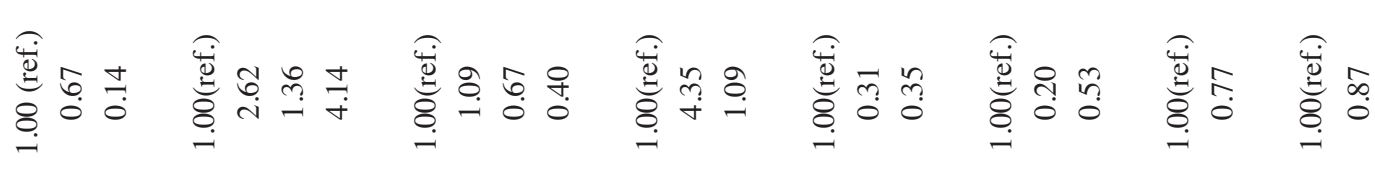

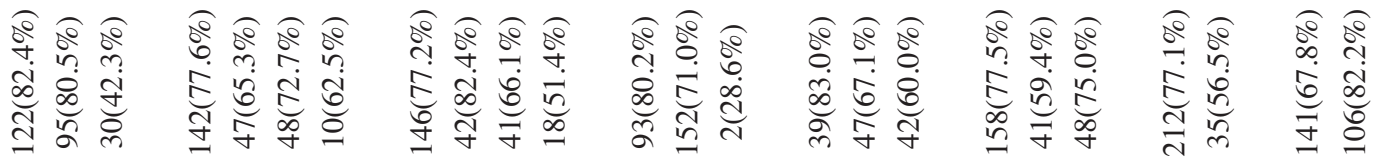

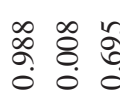

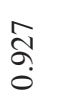

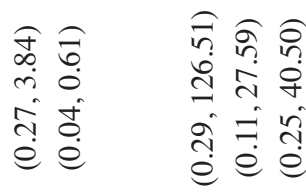

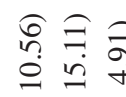

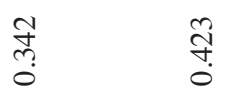

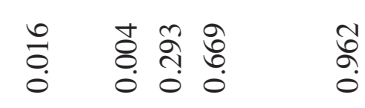

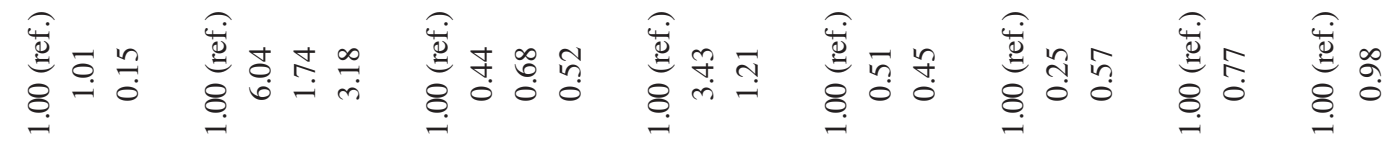

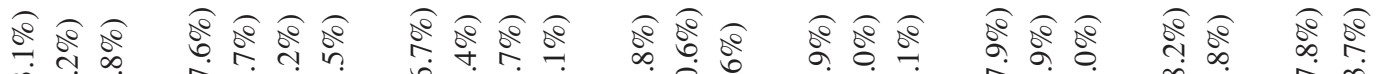

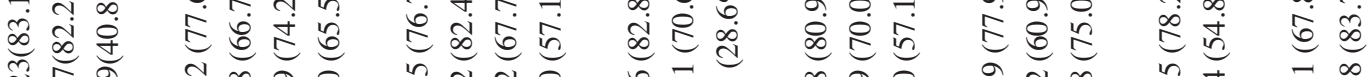
ป⿱一兀)

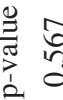<smiles>[SiH]=[SiH]</smiles><smiles>[C-]1C=C[CH-]1</smiles>

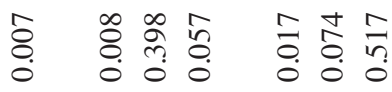
$\begin{array}{ll}\stackrel{n}{1} & \kappa \\ 0 & 0\end{array}$

(a)

\section{(1)}

0
8

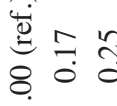

离

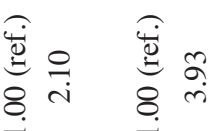


Table 3. Respondents Undergoing HPV Vaccination and Pap Smears Versus Demographics Variables (n=337)

\begin{tabular}{|c|c|c|c|c|c|c|c|c|}
\hline \multirow{2}{*}{$\begin{array}{l}\text { Respondents } \\
\text { Demographics }\end{array}$} & \multicolumn{4}{|c|}{ Respondents had HPV vaccination } & \multicolumn{4}{|c|}{ Respondents had done Pap Smear } \\
\hline & Yes $(\mathrm{n}(\%))$ & $\begin{array}{l}\text { Adjusted } \\
\text { OR }\end{array}$ & $95 \% \mathrm{CI}$ & p-value & Yes $(\mathrm{n}(\%))$ & $\begin{array}{c}\text { Adjusted } \\
\text { OR } \\
\end{array}$ & $95 \%$ CI & p-value \\
\hline Marital Status & & & & 0.071 & & & & 0.964 \\
\hline Single & $20(17.2 \%)$ & 1.00 (ref.) & & & $1(0.9 \%)$ & 1.00 (ref.) & & \\
\hline Married & $7(3.3 \%)$ & 0.00 & $(0,0)$ & & $106(49.5 \%)$ & $<0.01$ & $(0,0)$ & \\
\hline Divorced & $2(28.6 \%)$ & 0.00 & $(0,0)$ & & $4(57.1 \%)$ & $<0.01$ & $(0,0)$ & \\
\hline \multicolumn{2}{|c|}{ Number of Children } & & & 0.677 & & & & 0.598 \\
\hline No children & $4(8.5 \%)$ & 1.00 (ref.) & & & $18(38.3 \%)$ & 1.00 (ref.) & & \\
\hline $1-3$ children & $1(1.4 \%)$ & 0.24 & $(0.01,6.27)$ & & $37(52.9 \%)$ & 1.55 & $(0.64,3.73)$ & \\
\hline$\geq 4$ children & $1(1.4 \%)$ & 0.99 & $(0.03,38.10)$ & & $36(51.4 \%)$ & 1.51 & $(0.59,3.88)$ & \\
\hline Locality & & & & 0.425 & & & & 0.545 \\
\hline Urban & $19(9.3 \%)$ & 1.00 (ref.) & & & $63(30.9 \%)$ & 1.00 (ref.) & & \\
\hline Semi-Urban & $7(10.1 \%)$ & 13.13 & $(0.28,623.18)$ & & $24(34.8 \%)$ & 0.69 & $(0.32,1.50)$ & \\
\hline Rural & $3(4.7 \%)$ & 0.00 & $(0,0)$ & & $24(37.5 \%)$ & 0.70 & $(0.30,1.59)$ & \\
\hline Employment Statu & & & & 0.996 & & & & 0.565 \\
\hline Employed & $26(9.5 \%)$ & 1.00 (ref.) & & & $97(35.3 \%)$ & 1.00 (ref.) & & \\
\hline Unemployed & $3(4.8 \%)$ & 0.00 & $(0,0)$ & & $14(22.6 \%)$ & 0.73 & $(0.25,2.13)$ & \\
\hline Education & & & & 0.078 & & & & 0.269 \\
\hline $\begin{array}{l}\text { Non tertiary } \\
\text { level }\end{array}$ & $9(4.3 \%)$ & 1.00 (ref.) & & & $78(37.5 \%)$ & 1.00 (ref.) & & \\
\hline Tertiary level & $20(15.5 \%)$ & 33.67 & $(0.68,1672.50)$ & & $33(25.6 \%)$ & 1.52 & $(0.72,3.20)$ & \\
\hline
\end{tabular}

*Adjusted with age and ethnicity

the awareness on HPV virus.

On the awareness on the HPV vaccination, there were significant association based on age group and locality. Higher awareness were observed in groups lesser than 41 years old. Lower level on the HPV vaccination was observed in group whom are 41 years and above with the $95 \%$ CI value of less than one (0.03-0.65). In addition, there are more tendencies of respondents residing in the rural area compared to the semi-urban area to be more aware on the HPV vaccination. Other demographic factors like ethnicity, marital status, number of children, employment status and education level were not significant $(p<0.05)$ factors that are associated with the awareness on HPV vaccination.

\section{Awareness on cervical cancer, HPV virus and HPV vaccine} compared to the knowledge

Questions asked in relation to the awareness versus knowledge resulted in some significant association $(\mathrm{p}<0.05)$. About $279(82.8 \%)$ of respondents $(\mathrm{p}=0.040)$, are aware and know that cervical cancer start in the womb. In addition, about 164(48.7\%) of the respondents are aware and know that HPV is transmitted by sexual intercourse $(\mathrm{p}=0.02)$. There were $273(81.0 \%)$ know and aware that cervical cancer can be detected by Pap smear, 214(63.5\%) knew that HPV causes cervical cancer, 142(42.1\%) knew that HPV causes genital warts and HPV vaccine can be offered to female children aged 9 and above.

\section{Barriers of being vaccinated}

Majority of the respondents have indicated no time for vaccination $(41.2 \%)$, followed by expensive to get vaccinated $(40.1 \%)$ and not engaged in sexual relationship
$(37.1 \%)$. The three least reasons being the barriers of getting vaccinated are socially related such as no support from partner/family (9.5\%), worry of social stigma (7.7\%) and finally religious issues $(7.4 \%)$.

\section{Knowledge on pap smear}

Almost a larger percentage of the respondents have knowledge on Pap smear. About 295(87.5\%) provided the correct answer that Pap smear is performed to detect cervical cancer. Pap test is needed although no family history of cervical cancer 264(78.3\%). Pap smear is pelvic examination test 262(77.7\%). Healthy adult women should have Pap smear every two years 260(77.2\%).

\section{Had HPV vaccination and Pap smear}

Association between women who had HPV vaccine and Pap smear based on the demographic variables was performed (Table 3 ). There were insignificant associations between the number of children, locality, employment status and the education level for both that had HPV vaccination and Pap smear. However, it is important to note that very low percentage of respondents had HPV vaccination compared to those whom had Pap smear. Majority of the respondents whom had HPV vaccination are single (20 respondents), no children (4 respondents), residing in urban locality (19 respondents), employed (26 respondents) and having tertiary education level (20 respondents). On the other hand, majority of the respondents whom had Pap smear are married (106 respondents), with 1-3 children (37 respondents), residing in the urban locality (63 respondents), employed (97 respondents) and having non tertiary education level (78 respondents). More prominent practice to perform Pap 
smear were observed in group with 1-3 children with the OR of 1.55 and in the group with tertiary level of education with the OR of 1.52 .

\section{Discussion}

Majority of the respondents who participated in this study are Malay (54.3\%), Muslim (56.1\%), married $(63.5 \%)$, employed (81.6\%), having non tertiary education level $(61.8 \%)$ the belonging to the groups with either 1-3 children or 4 or more children (each $20.8 \%$ ) and residing in the urban locality $(60.5 \%)$.

The awareness on the cervical cancer, HPV virus and HPV vaccination is high which are $83.1 \%, 73.9 \%$ and $73.3 \%$ respectively. It is important to note that this study is done seven years after the vaccination was implemented in Malaysia and the awareness level has increased among the public. The results were similar to other studies from other countries that reported on the higher rates of the awareness which recorded the awareness levels of $57.6 \%$ to $84.3 \%$ (Christian et al., 2009; Jain et al., 2009). Low levels of awareness were also reported from other studies previously reported from general public in Malaysia on the awareness on HPV and HPV vaccine (Brewer and Fazekas, 2007; Wong, 2008; Sam et al., 2009; Wong, 2009; Al-Dubai et al., 2010).

Awareness on cervical cancer, HPV virus and HPV vaccine based on the respondents demographics are significantly associated with marital status $(\mathrm{p}=0.007)$, level of education level $(p=0.035)$ and the number of children $(p=0.057)$. The significant association of the marital status, number of children and level of education with awareness on cervical cancer, HPV virus and HPV vaccine corresponds to the results obtained by Al-Dubai et al. (2010). Education plays the vital role in disseminating the information on cervical cancer, HPV virus and vaccine. Therefore, educating both men and women from the schooling era are crucial as to provide them with a clearer understanding on the HPV and the importance of getting vaccinated (Calloway et al., 2006; Sherris et al., 2006) (Wong, 2010).

In relation to the awareness and the knowledge association of the respondents' majority of the knew that cervical cancer start in the womb $(82.8 \%)$, cervical cancer can be detected by Pap smear $(81.0 \%)$. However, there are still many who did not know that HPV causes cervical cancer $(63.5 \%), 57.9 \%$ did not know that HPV causes genital warts and HPV vaccine can be offered to female children aged 9 and above and $51.3 \%$ HPV is transmitted by sexual intercourse.

The main reason given as the barrier of getting vaccinated is no time to get vaccination $(41.2 \%)$, followed by expensive to get vaccinated $(40.1 \%)$ and not engaged in sexual relationship (37.1\%). The three least reasons being the barriers of getting vaccinated are socially related such as no support from partner/family (9.5\%), worry of social stigma (7.7\%) and finally religious issues $(7.4 \%)$. The majority of the respondents have indicated no time to get vaccination may due to lack of awareness of the importance of getting vaccinated and its relation to cervical cancer. The perspective from focus group study on HPV vaccine done in Malaysia have indicated the disappointment the governing body and the media had not made enough effort to educate the public on the importance and the dire need to get vaccinated (Wong, 2009).

Cost was the commonest reason chosen for not vaccinating (Sam et al., 2009; Goncalves et al., 2014; Rambout et al., 2014). The cost of the 3-dose vaccine was approximately RM1,634 (USD380) (1 US dollar =4.3 Malaysian Ringgit). The cost would pose financial burden especially in a household with many female children. Currently there is no funding assistance for adults to get vaccinated, therefore it is suggested to establish a vaccine assistance program especially for low-income groups as to make the vaccine accessible to everyone (Wong, 2009). In developing countries, with high cervical cancer incidences yet lack comprehensive screening programs, they may benefit most from the vaccination program (Sam et al., 2009).

Health care professional's recommendations and endorsement of the vaccine are important to initiate vaccine uptake. Thus, health professionals play a pivotal role to educate and introduce the HPV vaccine to women who present themselves in the health care settings (Wong, 2010).

In regards to the knowledge on Pap smear, over $75 \%$ of the respondents are knew that the test is performed to detect cervical cancer, is needed although no family history of cervical cancer, is a pelvic examination test and healthy women should have Pap test every two years.

The Pap smear screening program which was established in 1969 by the Ministry of Health, Malaysia (Ministry of Health, 2004). Malaysia relies on opportunistic screening delivery rather than an organized program to increase awareness of the disease (Othman and Rebolj, 2009). However, due to low screening uptake, there has been no reduction in the prevalence of cervical cancer noted to date (Othman and Rebolj, 2009).

It is important to note that through this study it was observed that very low percentage of respondents had HPV vaccination $(\mathrm{n}=29$ respondents $(8.6 \%)$ ) compared to those whom had Pap smear $(\mathrm{n}=111$ respondents $(32.9 \%))$ .Considering that the burden of cervical cancer is a global public health problem, WHO recommended the inclusion of routine HPV vaccination in the national immunization programs (WHO, 2009; Lim et al., 2014). This will beneficial as the HPV vaccines are shown to be effective and exhibits maximum efficacy if used by girls before pre-exposure to HPV (Faridi et al., 2011).

The main limitation of this study is the utilization of convenience sampling of population at a general hospital. Thus, the study respondents may be more aware of health issues, and in addition may not be nationally representative. Nevertheless, the sample was socioeconomically and ethnically diverse.

Conclusion/Recommendations, The low awareness on the HPV virus and HPV vaccination in terms of its relation to cervical cancer has to be addressed. Health care providers and the governing bodies have to play a vital role in disseminating the timely and correct information on the vaccine and the importance of getting vaccinated 
to the public more vigorously as to increase the number of women getting vaccinated against HPV. Further financial incentives could be provided to the adult females to get vaccinated.

State-wide joint initiatives involving the nongovernmental organization (NGO), public and the stakeholders such as implementation of media campaign will enable education on burden of HPV disease and HPV vaccination schedule. In addition, medical practitioners plays crucial role as they are the front liners in teaching on the importance of getting vaccinated to the public.

\section{Acknowledgements}

The study was not funded in whole or in part by any research grant or funding body. The authors would like to thank Director General of Health for the permission to publish this paper. Sincere thanks and appreciation to Professor Sami Abdo Radman Al-Dubai (Management and Science University) for providing the study validated questionnaire and the permission for use the questionnaire for this study.

\section{References}

Al-Dubai SAR, Alshagga MA, Al-Naggar RA, et al (2010). Knowledge, attitudes and barriers for human papilloma virus (HPV) vaccines among Malaysian women. Asian Pac J Cancer Prev, 11, 887-92.

Brewer N, Fazekas K (2007). Predictors of HPV vaccine acceptability: a theory-informed, systematic review. Prev Med, 45, 107-14.

Calloway C, Jorgensen CM, Saraiya M, et al (2006). A content analysis of news coverage of the HPV vaccine by the US newspaper. $J$ Womens Health, 15, 803-9.

Cheah P (1994). Human papillomavirus related diseases in Malaysians. Malaysian J Pathol, 16, 15-7.

Christian WJ, Christian A, Hopenhayn C (2009). Acceptance of the HPV vaccine for adolescent girls: Analysis of the state-added questions from the BRFSS.J Adolescent Health, 44, 437-45.

Faridi R, Zahra A, Khan K, et al (2011). Oncogenic potential of Human Papillomavirus (HPV) and its relation with cervical cancer. Virol J, 8, 269.

Gloria YH, Studentsov Y, Bierman R, et al (2004). Natural history of human papillomavirus type 16 virus like particle antibodies in young women. cancer epidemiology, Biomarkers Prev, 13, 110-6.

Goncalves AK, Cobucci RN, Rodrigues HM, et al (2014). Safety, tolerability and side effects of human papillomavirus vaccines: a systemic quantitative review. Brazilian $J$ Infectious Disease, 18, 651-9.

Jain N, Euler GL, Shefer A, et al (2009). Human papillomavirus (HPV) awareness and vaccination among women in the united states, national immunization Survey-Adult 2007. Prev Med, 48, 426-31.

Lim BK, Ng KY, Omar J, et al (2014). Immunogenicity and Safety of the AS04-adjuvanted human papillomavirus-16/18 cervical cancer vaccine in malaysian women aged 18-35 years: a randomized controlled Trial. Med J Malaysia, 69, $1-8$.

Othman N, Rebolj M (2009). Challenges to cervical cancer screening in a developing country: the case of Malaysia. Asian Pac J Cancer Prev, 10, 747-52.
Rambout L, Tashkandi M, Hopkins L, et al (2014). Self-reported barriers and facillitators to preventive human papillomavirus vaccination among adolescent girls and young women: a systemic review. Prev Med, 58, 22-32.

Sam I-C, Path MRC, Wong LP, et al (2009). Maternal acceptance of human papillomavirus vaccine in Malaysia. J Adolescent Health, 44, 610-2.

Schiffman M, Castle P, Jeronimo J, et al (2007). Human papillomavirus and cervical cancer. Lancet, 370, 890-907.

Sherris J, Friedman A, Wittet S, et al (2006). Chapter 25: Education, training and communication for HPV vaccines. Vaccines, 24, 210-8.

Wong LP (2008). Young Multiethnic women's attitute toward the HPV vaccine and HPV vaccination. Int J Gynaecol Obstetrics, 103, 131-5.

Wong LP (2009). Preventing cervical cancer through human papillomavirus vaccination : prespective from focus group. JLower Genital Tract Disease, 13, 85-93.

Wong LP (2010). Knowledge and Attitude about HPV infection, HPV vaccination and cervical cancer among rural southeast Asian women. Int Soc Behavioural Med, 18, 105-11. 